BEST EVIDENCE TOPIC REPORTS

\title{
Towards evidence based emergency medicine: best BETs from the Manchester Royal Infirmary
}

\author{
Edited by K Mackway-Jones
}

Emerg Med J 2006;23:300-303. doi: 10.1136/emj.2006.035121

Best Evidence Topic reports (BETs) summarise the evidence pertaining to particular clinical questions. They are not systematic reviews, but rather contain the best (highest level) evidence that can be practically obtained by busy practicing clinicians. The search strategies used to find the best evidence are reported in detail in order to allow clinicians to update searches whenever necessary. Each BET is based on a clinical scenario and ends with a clinical bottom line, which indicates, in the light of the evidence found, what the reporting clinician would do if faced with the same scenario again.

The BETs published below were first reported at the Critical Appraisal Journal Club at the Manchester Royal Infirmary or placed on the BestBETs website. Each BET has been constructed in the four stages that have been described elsewhere. ${ }^{2}$ The BETs shown here together with those published previously and those currently under construction can be seen at http://www.bestbets.org. ${ }^{3}$ Three BETs are included in this issue of the journal.

- Gammahydroxybuyrate overdose and physostigmine

- Terlipressin or sclerotherapy for acute variceal bleeding?

- Full blood count and reticulocyte count in painful sickle crisis

Carley SD, Mackway-Jones K, Jones A, et al. Moving towards evidence based emergency medicine: use of a structured critical appraisal journal club. J Accid Emerg Med 1998;15:220-222.

Mackway-Jones K, Carley SD, Morton RJ, et al. The best evidence topic report: A modified CAT for summarising the available evidence in emergency medicine. J Accid Emerg Med 1998;15:222-226.

Mackway-Jones K, Carley SD. bestbets.org: Odds on favourite for evidence in emergency medicine reaches the worldwide web. J Accid Emerg Med 2000;17:235-6

\section{Gammahydroxybutyrate overdose and physostigmine}

\section{Report by Liz Allen, Specialist Registrar Checked by Walid Alsalim, Specialist Registrar Ipswich Hospital, UK \\ doi: $10.1136 / \mathrm{emj} .2006 .035139$}

\section{Abstract}

A short cut review was carried out to establish whether physostigmine has a role in the management of gammahydroxybutyrate (GHB) ingestion. 18 papers were found using the reported searches, of which one was a review that incorporated all other relevant papers. The author, date and country of publication, patient group studied, study type, relevant outcomes, results, and study weaknesses of this review are tabulated. It is concluded that the evidence for the use of physostigmine for the treatment of GHB ingestion is poor. Local advice should be followed.

\section{Three part question}

In [patients with gammahydroxybutyrate ingestion] does [treatment with physostigmine] [reduce the neccessity for intubation and duration of unconsciousness]?

\section{Clinical scenario}

A 25 year old man is brought to the emergency department after collapsing in a club. His friends report ingestion of Gammahydroxybutyrate (GHB) and alcohol. His Glasgow Coma Scale score is 3 on arrival and he is intermittently apnoeic. When you attempt to intubate him he seems to rouse but quickly becomes unresponsive again once you stop. You ask for anaesthetic help. The anaesthetic registrar has a similar experience on attempting intubation. You are sure you have read that physostigmine can be used to avoid intubation in this situation. You wonder if you have remembered correctly.

\section{Search strategy}

MEDLINE using the OVID interface 1966 to January Week 1 2006

Embase using the OVID interface 1980 to 2006 Week 02

[exp Hydroxybutyrates/OR GHB.mp OR gammahydroxybutyrate.mp.] AND [physostigmine.mp. or exp Physostigmine/] Limit to Humans and English Language

The Cochrane Library Issue 42005

[Hydroxybutyrates $\{\mathrm{MeSH}$ explode all trees $\}$ OR gammahydroxybutyrate $\{$ all fields $\}$ ] AND [physostigmine $\{\mathrm{MeSH}$ explode all trees $\}$.

\section{Search outcome}

18 papers were found of which one was a systematic review. All other relevant papers were included in the review.

\section{Comment(s)}

As noted in the review by Traub et al, the evidence for and against the use of physostigmine is of poor quality. Only two papers (involving six patients) are set in the emergency department, while those in the anaesthetic room are uncontrolled. This matters since the recovery from GHB induced anaesthesia is relatively rapid and it is therefore difficult to draw conclusions from uncontrolled studies.

\section{- CLINICAL BOTTOM LINE}

The evidence for the use of physostigmine is of low quality. Local advice should be followed.

Traub SJ, Nelson LS, Hoffman RS. Physostigmine as a treatment for Gamma Hydroxybutyrate Toxicity: A Review. Journal of Toxicology - Clinical Toxicology 2002;40(No 6):781-7. 
Table 1

\begin{tabular}{|c|c|c|c|c|c|}
\hline $\begin{array}{l}\text { Author, date, } \\
\text { and country }\end{array}$ & Patient group & Study type & Outcomes & Key results & Study weaknesses \\
\hline $\begin{array}{l}\text { Traub S, et al, } \\
2002 \text {, USA }\end{array}$ & $\begin{array}{l}4 \text { papers reporting the effect } \\
\text { of physostigmine on GHB } \\
\text { affected patients }\end{array}$ & Systematic review & $\begin{array}{l}6 \text { Emergency Department } \\
\text { patients as case reports } \\
67 \text { anaesthetised patients } \\
\text { in two case series ( } 25 \text { and } 42 \\
\text { patients) }\end{array}$ & $\begin{array}{l}5 \text { said to have } \\
\text { improved } \\
60 \text { patients awake } \\
\text { within } 10 \text { minutes }\end{array}$ & $\begin{array}{l}\text { Case reports and } \\
\text { uncontrolled, unblinded } \\
\text { series only. } \\
\text { Anaesthetised patients } \\
\text { had many drugs }\end{array}$ \\
\hline
\end{tabular}

\section{Terlipressin or sclerotherapy for acute variceal bleeding?}

\section{Report by Duncan McAuley, Consultant Checked by Usman Jaffer, Surgical SHO Addenbrookes Hospital, Cambridge, UK doi: $10.1136 / \mathrm{emi} .2006 .035147$}

\section{Abstract}

A short cut review was carried out to establish whether terlipressin or sclerotherapy is more effective at reducing acute bleeding and mortality in acute oesophageal variceal bleeding. 327 papers were found using the reported searches, of which one presented the best evidence to answer the clinical question. The author, date, and country of publication, patient group studied, study type, relevant outcomes, results, and study weaknesses of this best paper is tabulated. It is concluded that terlipressin may be as effective as sclerotherapy in acute variceal bleeding and should certainly be considered if there is delay to endoscopy.

\section{Clinical scenario}

A 56 year old patient with known oesophageal varices presents to the emergency department with a large haematemesis. Despite your best efforts you cannot organise endoscopy in less than 4 hours. You wonder whether terlipressin (glypressin) is an effective alternative to sclerotherapy.

\section{Three part question}

In [adults with known varices] is [terlipressin or sclerotherapy] more effective at [reducing acute bleeding and mortality]?

\section{Search strategy}

MEDLINE using the OVID interface 1966 to January Week 1 2006

Embase using the OVID interface 1980 to 2006 Week 02

[varice\$.mp. OR exp Gastrointestinal Hemorrhage/OR exp "Esophageal and Gastric Varices"/] AND [sclerotherapy.mp. or exp Sclerotherapy/OR exp Hemostasis, Endoscopic/] AND [glypressin.mp. OR terlipressin.mp. OR vasopressin.mp. OR exp Vasopressins/] LIMIT to Humans and English Language and Abstracts only

The Cochrane Library Issue 42005

[esophageal and gastric varices $\{\mathrm{MeSH}$ explode all trees $\}$ ] AND [sclerotherapy $\{\mathrm{MeSH}$ explode all trees $\}$ ] AND [vasopressins $\{\mathrm{MeSH}$ explode all trees\} OR glypressin \{all fields\} OR terlipressin \{all fields\} OR lypressin \{all fields $\}$ ].

\section{Search outcome}

327 papers found of which three were relevant. One metaanalysis and one Cochrane review (by the same authors) referred to the single RCT quoted below

\section{Comment(s)}

Only one randomised controlled trial was found. No significant difference in control of bleeding or mortality was demonstrated; there was a trend towards fewer side effects with terlipressin.

\section{- CLINICAL BOTTOM LINE}

Terlipressin (glypressin) may well be as effective as sclerotherapy for acute variceal bleeds. It could be considered when there is a delay to endoscopy. Many centres now use band ligation rather than sclerotherapy; this has not been compared to vasoactive drugs.

Escorsell A, Ruiz del Arbol L, Planas R, et al. Multicenter Randomised Controlled Trial of Terlipressin versus Sclerotherapyin the Treatment of Acute variceal Bleeding: the TEST study. Hepatology 2000;32(3):471-476.

\section{Table 2}

\begin{tabular}{|c|c|c|c|c|c|}
\hline $\begin{array}{l}\text { Author, date, } \\
\text { and country }\end{array}$ & Patient group & Study type & Outcomes & Key results & Study weaknesses \\
\hline \multirow[t]{3}{*}{$\begin{array}{l}\text { Escorsell A, et al, } \\
2000 \text {, Spain }\end{array}$} & \multirow[t]{3}{*}{$\begin{array}{l}219 \text { cirrhotic patients with } \\
\text { endoscopy proven variceal } \\
\text { bleeding. }\end{array}$} & \multirow[t]{3}{*}{$\begin{array}{l}\text { Multi-centre unblinded } \\
\text { randomised controlled } \\
\text { trial }\end{array}$} & $\begin{array}{l}\text { 48-hour failure to } \\
\text { control bleeding }\end{array}$ & $\begin{array}{l}\text { Failure rates were } 33 \% \\
\text { for terlipressin and } 32 \% \\
\text { for sclerotherapy (not } \\
\text { significant) } \\
\text { Rebleeding rates were the } \\
\text { same (14\% vs } 14 \% \text { ) }\end{array}$ & $\begin{array}{l}\text { Not blinded, ie } \\
\text { assessors of outcomes } \\
\text { not clearly blinded to } \\
\text { treatment allocation. }\end{array}$ \\
\hline & & & 42 day mortality rate & $\begin{array}{l}26 \text { out of } 105 \text { terlipressin } \\
\text { patients died versus } 19 \\
\text { of the } 114 \text { sclerotherapy } \\
\text { patients (not significant) }\end{array}$ & \multirow[t]{2}{*}{$\begin{array}{l}\text { Intention-to-treat } \\
\text { analysis not stated }\end{array}$} \\
\hline & & & Pre-defined side effects & $\begin{array}{l}\text { Trend towards more side } \\
\text { effects with sclerotherapy } \\
(30 \% \vee 20 \%, p=0.6)\end{array}$ & \\
\hline
\end{tabular}

